The University of Maine

DigitalCommons@UMaine

Maine-Syracuse Longitudinal Papers

Maine-Syracuse Longitudinal Study

Spring 2005

\title{
Blood Pressure and Cognitive Function in an African-American and a Caucasian-American Sample: The Maine-Syracuse Study
}

\author{
Michael A. Robbins \\ University of Maine - Main, robbins@maine.edu \\ Merrill F. Elias \\ University of Maine - Main, mfelias@maine.edu \\ Penelope K. Elias \\ Marc M. Budge
}

Follow this and additional works at: https://digitalcommons.library.umaine.edu/ longitudinal_papers

Part of the Cardiovascular System Commons, and the Cognitive Psychology Commons

\section{Repository Citation}

Robbins, M. A., Elias, M. F., Elias, P. K., \& Budge, M. M. (2005). Blood pressure and cognitive function in an African-American and Caucasian-American sample: The Maine-Syracuse Study. Psychosomatic Medicine, 67, 707-714.

This Article is brought to you for free and open access by DigitalCommons@UMaine. It has been accepted for inclusion in Maine-Syracuse Longitudinal Papers by an authorized administrator of DigitalCommons@UMaine. For more information, please contact 


\title{
Blood Pressure and Cognitive Function in an African-American and a Caucasian-American Sample: The Maine-Syracuse Study
}

\author{
Michael A. Robbins, PhD, Merrill F. Elias, PhD, MPH, Penelope K. Elias, PhD,
} and Marc M. Budge, MBBS, BMedSc, FRACP

\begin{abstract}
Objective: The primary purpose of this study was to examine associations between indices of blood pressure (BP) and cognitive function for African-American participants in the Maine-Syracuse Longitudinal Study (MSLS). Corresponding data for the Caucasian-American MSLS participants were included to provide a basis for comparison. Interactions of age with BP indices were also assessed in relation to cognitive function. Methods: Data were drawn from the baseline MSLS questionnaires, medical interviews and examinations, Wechsler Adult Intelligence Scale subtests, and measurements of BP for 1563 participants, of whom 147 were African American. Multiple linear regression analyses were employed to examine the relationship between several BP predictors and cognitive outcomes with statistical adjustment for demographic, psychosocial, and cardiovascular risk factors. Results: Significant inverse associations between BP indices and cognitive performance were obtained for both racial cohorts but were generally of higher magnitude for the African-American cohort. Interactions of BP with age were not obtained for any of the cognitive test scores. Conclusions: Elevations in BP are associated with poorer cognitive function for African-American and Caucasian-American cohorts. These associations are similar for younger and older participants. Key words: African American, blood pressure, hypertension, cognitive function.
\end{abstract}

BP = blood pressure; MSLS = Maine-Syracuse Longitudinal Study; WAIS = Wechsler Adult Intelligence Scale; SBP = systolic blood pressure; DBP = diastolic blood pressure.

\section{INTRODUCTION}

A pproximately $30 \%$ of the adult population in the United States, an estimated sixty-five million people, has arterial hypertension (1). Hypertension poses an increased risk for myocardial infarction, congestive heart failure, end-state renal disease, and stroke (2-5). Recent reviewers conclude that hypertension is also a risk factor for lowered cognitive functioning, and that functional and structural changes in the brain that accompany hypertension are a likely basis for this association $(6,7)$. This research on hypertension and blood pressure (BP) in relation to cognitive performance has been conducted primarily with Caucasian samples. Consequently little information for African Americans is available (8).

Further research on relations between indices of BP level and cognitive functioning for African Americans is important because the prevalence and incidence of hypertension for African Americans is higher than the levels observed for other racial groups in the US $(1,9,10)$. Beginning in young adulthood, and continuing across the adult life-span, African Americans have higher BP values than other racial groups (9). This phenomenon is related to the higher prevalence and incidence of cardiovascular mortality and morbidity, including vascular dementia, experienced by African Americans (11-13).

Although the higher prevalence of hypertension among African Americans emerges in early adulthood, most studies

From the Department of Psychology, University of Maine, Orono, ME (M.A.R., M.F.E., P.K.E.); Department of Mathematics and Statistics, Boston University, Boston, MA (M.F.E.); Department of Geriatric Medicine, Australian National University Medical School, Canberra, Australia (M.M.B.).

Address correspondence and reprint requests to Michael A. Robbins, Department of Psychology, 5742 Little Hall, University of Maine, Orono, ME 04469-5742. E-mail: mar@umit.maine.edu

Preparation of this manuscript was supported by National Institute on Aging project AG03055 and National Heart, Lung, and Blood Institute project HL67358.

Received for publication July 13, 2004; revision received March 18, 2005; date accepted March 24, 2005.

DOI: 10.1097/01.psy.0000171164.50990.80 of BP and cognitive functioning in African Americans have included only middle-aged and older subjects and/or limited cognitive test batteries $(8,14-17)$, and results have been mixed.

In one study with an African-American sample (age range 43-82 years), investigators reported relations between only one of six neuropsychological tests and either systolic BP (SBP) or diastolic BP (DBP) (8). Counter to expectations based on the literature $(6,7)$, higher DBP was related to better performance on the Digits Forward test.

Other investigations have reported comparative data for African-American participants in large multi-racial samples (14-17), although for limited cognitive test batteries. The Short Portable Mental Status Questionnaire, a 10 item screening instrument for cognitive functioning, was used to examine cognitive change over a 3 year period in relation to measured BP for one large sample of African Americans and Caucasian Americans (age 65 or over at baseline) (14). Curvilinear associations were obtained such that SBP values in the intermediate range were associated with better performance, and both low and high SBP values were associated with poorer performance. This pattern was obtained for both racial samples, but the relationship was statistically significant only for the Caucasian Americans. Four cognitive measures were used in another investigation for which the large biracial sample comprised participants age 65 or older (16) Both high and low SBP and DBP were associated with poorer performance on each of the four cognitive measures when compared with intermediate BP levels. The majority of participants (61.8\%) were African American and results were not affected by statistical adjustment for race.

Knopman et al. (15) used three cognitive tests to examine 6-year change in performance in relation to BP for a large biracial sample age 47 to 70 years at baseline (15). They found that the higher the BP, the greater the decline on the test of psychomotor speed, although this relationship was nonsignificant within the African-American cohort. Finally, three cognitive tests were used in a recent study with a large multi-racial sample that included younger and middle-aged participants (age 20-59 years) (17). One linear result, relating 
higher BP to poorer performance on serial digit learning was obtained. A race/ethnicity variable, formed by combining African American and other minority groups for comparison with nonHispanic Caucasian Americans, did not moderate this association. However, age cohort did moderate this association (i.e., relations between $\mathrm{BP}$ and cognitive performance were found only for 20-39 year-old participants and not for the participants who were 40-59 years of age).

In summary, findings are equivocal with respect to associations between BP and cognitive functioning for African Americans, the range of cognitive domains assessed has been fairly narrow, and we are aware of only one study that included younger participants and reported a multiplicative relation between BP and age (17).

The importance of examining the possibility that age moderates the relationship between BP and cognitive performance has been clearly established. One major review of the literature from a life span perspective has concluded that although inverse associations between $\mathrm{BP}$ and cognitive function are found among adults of all ages, there is conflicting evidence with respect to whether these associations are stronger for particular age cohorts (18).

Most cross-sectional studies have reported stronger associations for BP and cognitive performance for their younger or middle-aged cohorts relative to their middle-aged or older cohorts $(17,19-21)$. One early longitudinal study with participants conducted 60 years ago found BP relations to cognitive decline to be stronger for its older cohort (22), and our most recent longitudinal study (23) found that BP-related decline in cognitive performance was the same for younger (age 18 to 46 years) and older (age 47 to 83 years) groups. Although findings have been inconsistent, it has been hypothesized that the physiological mechanisms underlying associations between $\mathrm{BP}$ and cognitive functioning may differ for younger and older cohorts $(6,18)$. For younger cohorts the underlying mechanisms are more likely to be BP effects on neurophysiological function (e.g., cerebral blood flow, cerebral metabolism, autoregulation), or sympathetic nervous system or neuroendocrine arousal. For older cohorts the underlying mechanisms may involve structural change, such as atherosclerosis, atrophy, or white matter disease $(6,18)$.

Because the physiological concomitants of higher BP are similar for African Americans and Caucasian Americans (9) our working hypotheses were that (a) inverse linear associations between BP variables and cognitive performance level would be obtained for both racial groups; (b) the pattern of relations between BP and specific cognitive abilities would be similar; and (c) if age cohort differences emerged in associations between BP and cognitive functioning, these associations would be stronger for younger participants.

\section{METHODS \\ Participants}

The study samples compared were composed of community-dwelling nonHispanic African-American and Caucasian-American residents of upstate New York who participated in the Maine/Syracuse Longitudinal Study
(MSLS) between 1976 and $2002(23,24)$. The MSLS was approved by the Institutional Review Boards at SUNY Upstate Medical University and the University of Maine. Initial criteria for exclusion from the MSLS include treatment for alcoholism or drug abuse, or a psychiatric history (23). From the initial pool of 1945 African-American and Caucasian-American subjects, additional exclusions were made for this study. Because all African-American subjects were under the age of 80 , Caucasian-American subjects age 80 and above $(n=46)$ were excluded to make the age ranges equivalent. Other bases for exclusion were (a) secondary hypertension $(n=32)(24)$; (b) difficulties in speaking and reading English $(n=6)$; (c) an extreme SBP value of 300 $\mathrm{mm} \mathrm{Hg}(n=1)$; (c) missing data for one or more covariates (primarily depression scale scores, $n=66$; trait anxiety scores, $n=73$; or body mass indices, $n=124$ ) used in the expanded regression models described below. Inclusion of these participants in the sample did not alter the results. Of the 1661 subjects remaining, those with the following health conditions were excluded in order to reduce the extent of comorbid illness in the sample: (a) confirmed cerebrovascular disease, including clinical stroke $(n=23)$; (b) confirmed cardiovascular disease ( $n=43)$; (c) kidney disease $(n=5)$; and (d) other major disease, such as cancer $(n=27)$. Inclusion of these individuals with comorbid illness in the sample did not alter the results for analyses conducted with the remaining 1563 participants, of whom 147 were African Americans.

\section{Procedure}

Blood pressure data were obtained as a part of studies of the endocrine bases of hypertension conducted in conjunction with the cognitive studies (24). With Institutional Review Board approval, participants were asked to withdraw from their antihypertensive medications from 3 to 21 days before testing with the permission and under the direction of their personal physician and with careful supervision by the study physician. Withdrawal from medication was an aspect of the endocrine diagnostic protocol for the medical studies conducted in parallel and in collaboration with cognitive data collection. Whether participants were withdrawn from medication at all, as well as the number of days of withdrawal from medication, was determined by the supervising physicians on an individual basis for each participant. For all participants, a demographics questionnaire (age, education, occupation), the Spielberger State-Trait Anxiety Inventory (25), the Zung Depression Scale (26), the Cornell Medical Index (27), and a scale assessing tobacco and alcohol use were administered before a medical interview and measurement of height and weight. Classification of diabetes mellitus was based on the medical interview and required a history of pharmacological treatment. Blood pressure was then measured using a Critikon Dinamap 1846SX automated BP monitor. The optimal cuff size for each individual was used (28). Blood pressure variables used for analyses were based on the average of 6 sitting, 6 recumbent, and 6 standing $\mathrm{BP}$ measurements taken at this test session. Following BP assessment the tests of cognitive functioning were administered by a trained psychological examiner.

\section{Design and Data Analysis Outcome Variables}

The dependent (cognitive outcome) variables were the Wechsler Adult Intelligence Scale (WAIS) tests of Information, Similarities, Digit Span Forward, Digit Span Backward, Digit Symbol Substitution, and Block Design (29). Unlike several previous studies of BP and cognitive performance from our laboratory (e.g., 6,23), not all WAIS subtests were available for this study. The subtests used were those administered at baseline to all participants throughout the MSLS. Raw scores for each test were converted to standard (z) scores so that increments for each score would be expressed in SD units. These WAIS tests assess a wide variety of cognitive abilities: (a) information measures retention of general information; (b) similarities measures verbal concept formation and general mental ability; (c) Digit Span Forward measures attention and immediate memory span; (c) Digit Span Backward measures attention, immediate memory span, and ability to double track; (d) Digit Symbol Substitution measures attention, visual-motor coordination, and response speed; and (e) Block Design measures spatial perception and organization. These six WAIS scores were summed, and the sum was converted to 


\section{AFRICAN-AMERICAN BLOOD PRESSURE AND COGNITION}

a standard ( $\mathrm{z}$ ) score, to produce an index of global cognitive functioning. Separate multiple regression analyses were conducted for the composite cognitive test score and for the individual cognitive test scores.

\section{Predictor Variables}

The BP predictor variables, SBP $(\mathrm{mm} \mid \mathrm{Hg})$, DBP $(\mathrm{mm} \mid \mathrm{Hg})$, and pulse pressure $(\mathrm{mm} \mid \mathrm{Hg})$, were entered into separate analyses along with relevant interactions and covariates.

\section{Covariates}

Recent reviewers of this literature have stressed the importance of accounting for demographic variables such as age, education, and gender when examining associations between BP and cognitive performance $(6,7)$. Consequently we employed multivariable regression models (basic models) that consisted of one of the BP variables and the following covariates: (a) age (in years); (b) education (in years); (c) gender (0 = male, $1=$ female); (d) occupation (level); and (e) racial cohort $(0=$ African American, $1=$ Caucasian American). Occupation was coded on a scale from 1 (unskilled) to 6 (executive/professional). There are additional correlates of BP and cognitive performance that should be considered for inclusion in statistical models as covariates $(6,7)$. We chose candidate covariates based on the literature for examination in preliminary correlation analyses. To be included in the expanded models, each candidate covariate was required to be significantly correlated with one or more of the BP predictor variables or cognitive performance variables $(p<.05)$. In addition to the demographic variables in the basic model, the expanded model comprised the following: (a) antihypertensive medication use ( $0=$ no, 1 = yes); (b) alcohol consumption (drinks per week); (c) cigarette smoking (number per week); (d) psychotropic medication use $(0=$ no, $1=$ yes $) ; 5)$ diabetes mellitus $(0=$ no, $1=$ yes $)$; (e) body mass index $\left(\mathrm{kg} / \mathrm{m}^{2}\right)$; (f) trait anxiety scores; and (g) depressive symptom scores.

\section{Tests of Interactions}

Interaction terms were calculated as product vectors and entered into each model in a hierarchical manner after the main effects and covariates (30). The interaction terms of interest to the study were those that involved age in conjunction with BP variables and Race. Thus, for example, where SBP was in the model as a main effect we examined the two-way interactions of SBP by race, SBP by age, and race by age, as well as the three-way interaction of SBP by race by age. The statistical test of the two-way interaction terms (i.e., SBP by race, SBP by age, and race by age) were controlled for the main effects of SBP and covariates in the model. The statistical test of the threeway interaction term (i.e., SBP by race by age) was adjusted for all main effects and the constituent two-way interaction terms. The same approach was used for DBP and pulse pressure. Alternate analyses were performed in which age was represented either as a continuous variable or as an age group vector, with the age groups based on a median split (age 49 years).

\section{RESULTS}

Descriptive information for the predictor variables, covariates, and cognitive outcome variables are presented in Table 1. For both racial samples, occupation levels range from unskilled to executive and professional, and a wide range of age and education levels are represented. As may be seen in Table 1 , in comparison to the Caucasian-American sample, the African-American sample was on average younger and lower in education and occupation level. African-American participants had higher values for the body mass index, higher scores on the measure of depressive symptoms, and lower cognitive test scores. They were less likely to consume alcohol, but were more likely to smoke cigarettes, be diabetic, and use prescribed psychotropic medications. The only difference with respect to the BP variables was for DBP, for which AfricanAmerican participants had a higher mean value. The propor- tion of participants using antihypertensive medication was equivalent for the two samples.

Hypertensive African Americans $(n=80)$ did not differ from hypertensive Caucasian Americans $(n=785)$ with respect to either self-reported duration of hypertension $(p>.80)$ or number of days withdrawn from antihypertensive medication before testing $(p>.35)$. Preliminary analyses were conducted in which the number of days that hypertensive participants were withdrawn from medications was examined as a covariate. This variable was not included in the final model because it did not show statistically significant associations with any of the cognitive variables and did not affect the results either for BP variables or for use of antihypertensive medication.

Examination of the correlations among covariates provided no indication of colinearity (31). The highest Pearson correlations obtained were between Zung Depression Scores and Trait Anxiety scores $(r=.62$ to $r=.66)$. Correlations between education and occupation ranged from $r=.41$ and $r=.44$. All other correlations were less than $r=.30$.

Figure 1 and 2 display scatter plots of Global Composite scores in relation to SBP for the African-American and Caucasian-American sample, respectively. For display purposes, in these plots the Global Composite score is expressed as a $t$ score (z score plus 10). These plots illustrate our findings that associations in this study are best described by linear functions. Quadratic BP terms and strata of BP values (JNC-7 BP categories (32) and quintiles of SBP and DBP), were analyzed separately to determine whether low, as well as high, BP values were related to cognitive functioning. Lower $\mathrm{BP}$ values were not associated with poorer performance for any of the WAIS measures.

\section{Major Results}

The two- and three-way interaction terms involving age with $\mathrm{BP}$ and/or race were all nonsignificant ( $p$ values $>.10$ ). This was true whether continuous age was used or an age group vector representing younger and older participants based on a median split was used. However, significant two-way interactions of race with SBP and DBP were obtained for the majority of the cognitive outcome variables $(p$ s $<0.05)$.

These interactions are illustrated in Table 2, which shows results for the regression of WAIS scores on SBP. Regression coefficients for the African-American and Caucasian-American samples, respectively (first two columns), are adjusted for the effects of all covariates in the basic model. The corresponding regression coefficients (third and fourth column) are adjusted for the effects of all covariates in the expanded model. Regression coefficients presented in bold type indicate that the SBP by race interaction was significant for that specific cognitive outcome variable. Importantly, even when the BP by race interaction was significant, significant inverse associations between BP and cognitive performance for each racial sample remained. Results for the Global Composite measure illustrate this point. With adjustment for the covari- 
ROBBINS et al.

TABLE 1. Characteristics of the Total, African-American, and Caucasian American Samples

\begin{tabular}{|c|c|c|c|c|}
\hline \multirow[b]{2}{*}{ Variable } & \multicolumn{3}{|c|}{ Sample } & \multirow[b]{2}{*}{$p^{a}$} \\
\hline & $\begin{array}{c}\text { Overall } \\
(n=1563)\end{array}$ & $\begin{array}{l}\text { African American } \\
\quad(n=147)\end{array}$ & $\begin{array}{l}\text { Caucasian American } \\
\quad(n=1416)\end{array}$ & \\
\hline \multicolumn{5}{|l|}{ Systolic BP (mm|Hg) } \\
\hline Mean & 137.9 & 139.2 & 137.8 & ns \\
\hline SD & 27.6 & 29.7 & 27.4 & \\
\hline Range & $85-272$ & $96-260$ & $85-272$ & \\
\hline \multicolumn{5}{|l|}{ Diastolic BP $(\mathrm{mm} \mid \mathrm{Hg})$} \\
\hline Mean & 81.5 & 84.5 & 81.2 & .05 \\
\hline SD & 18.1 & 20.4 & 17.8 & \\
\hline Range & $44-160$ & $48-160$ & $44-146$ & \\
\hline \multicolumn{5}{|l|}{ Pulse pressure $(\mathrm{mm} \mid \mathrm{Hg})$} \\
\hline Mean & 56.4 & 54.7 & 56.6 & ns \\
\hline SD & 16.9 & 15.1 & 17.1 & \\
\hline Range & $22-161$ & $25-113$ & $22-161$ & \\
\hline \multicolumn{5}{|l|}{ Age (years) } \\
\hline Mean & 49.1 & 43.4 & 49.7 & .001 \\
\hline SD & 15.0 & 10.7 & 15.2 & \\
\hline Range & $18-79$ & $18-76$ & $18-79$ & \\
\hline \multicolumn{5}{|l|}{ Education (years) } \\
\hline Mean & 14.2 & 12.6 & 14.4 & .001 \\
\hline SD & 2.7 & 2.5 & 2.6 & \\
\hline Range & $5-20$ & $5-20$ & $6-20$ & \\
\hline \multicolumn{5}{|l|}{ Occupation (level) } \\
\hline Mean & 4.4 & 3.7 & 4.4 & .001 \\
\hline SD & 1.4 & 1.6 & 1.3 & \\
\hline Range & $2-6$ & $2-6$ & $2-6$ & \\
\hline \multicolumn{5}{|l|}{ Depressive symptoms } \\
\hline Mean & 42.6 & 46.2 & 42.2 & .001 \\
\hline SD & 9.6 & 10.5 & 9.4 & \\
\hline Range & $25-84$ & $28-84$ & $25-84$ & \\
\hline \multicolumn{5}{|l|}{ Trait anxiety } \\
\hline Mean & 35.1 & 36.1 & 35.0 & ns \\
\hline SD & 9.1 & 9.2 & 9.1 & \\
\hline Range & $20-74$ & $21-71$ & $20-74$ & \\
\hline \multicolumn{5}{|l|}{ Body mass index $\left(\mathrm{kg} / \mathrm{m}^{2}\right)$} \\
\hline Mean & 27.8 & 30.6 & 27.6 & .001 \\
\hline SD & 5.7 & 7.2 & 5.4 & \\
\hline Range & $15.8-61.3$ & $17.8-61.3$ & $15.8-53.0$ & \\
\hline Gender (\% Female) & 56.7 & 61.2 & 56.2 & ns \\
\hline Alcohol use (\% current) & 44.2 & 29.3 & 45.8 & .01 \\
\hline Smoker (\% current) & 13.5 & 23.1 & 12.5 & .001 \\
\hline Antihypertensive medication (\%) & 37.4 & 42.2 & 36.9 & ns \\
\hline Treatment for diabetes (\%) & 4.1 & 9.5 & 3.5 & .01 \\
\hline Psychotropic medication use (\%) & 5.9 & 10.9 & 5.4 & .01 \\
\hline \multicolumn{5}{|l|}{ Global composite ( $z$ score) } \\
\hline Mean & 0.00 & -1.06 & 0.10 & $<.001$ \\
\hline SD & 1.00 & 1.14 & 0.89 & \\
\hline Range & $-4.87-2.31$ & $-4.87-1.87$ & $-3.74-2.31$ & \\
\hline \multicolumn{5}{|l|}{ Block design } \\
\hline Mean & 34.5 & 27.2 & 35.2 & $<.001$ \\
\hline SD & 8.2 & 9.0 & 7.8 & \\
\hline Range & $0-48$ & $0-46$ & $12-48$ & \\
\hline \multicolumn{5}{|l|}{ Digit symbol } \\
\hline Mean & 56.7 & 49.8 & 57.4 & $<.001$ \\
\hline SD & 12.8 & 13.8 & 12.4 & \\
\hline Range & $11-90$ & $11-90$ & $12-90$ & \\
\hline \multicolumn{5}{|l|}{ Information } \\
\hline Mean & 19.4 & 13.6 & 20.0 & $<.001$ \\
\hline SD & 5.1 & 6.0 & 4.6 & \\
\hline Range & $2-29$ & $4-27$ & $2-29$ & \\
\hline & & & & (Continued) \\
\hline
\end{tabular}


TABLE 1. (Continued)

\begin{tabular}{|c|c|c|c|c|}
\hline \multirow[b]{2}{*}{ Variable } & \multicolumn{3}{|c|}{ Sample } & \multirow[b]{2}{*}{$p^{a}$} \\
\hline & $\begin{array}{c}\text { Overall } \\
(n=1563)\end{array}$ & $\begin{array}{l}\text { African American } \\
\qquad(n=147)\end{array}$ & $\begin{array}{l}\text { Caucasian American } \\
\quad(n=1416)\end{array}$ & \\
\hline \multicolumn{5}{|l|}{ Similarities } \\
\hline Mean & 17.3 & 14.5 & 17.6 & $<.001$ \\
\hline SD & 6.9 & 4.8 & 3.9 & \\
\hline Range & $0-26$ & $0-24$ & $2-26$ & \\
\hline \multicolumn{5}{|l|}{ Digit span forward } \\
\hline Mean & 6.9 & 6.4 & 6.9 & $<.001$ \\
\hline SD & 1.3 & 1.2 & 1.2 & \\
\hline Range & $3-9$ & $4-9$ & $3-9$ & \\
\hline \multicolumn{5}{|l|}{ Digit span backward } \\
\hline Mean & 5.1 & 4.2 & 5.2 & $<.001$ \\
\hline SD & 1.4 & 1.5 & 1.4 & \\
\hline Range & $0-8$ & $2-8$ & $0-8$ & \\
\hline
\end{tabular}

${ }^{a}$ Comparison between African-American and Caucasian American samples, $t$ test for means and $\chi^{2}$ test for percentages.

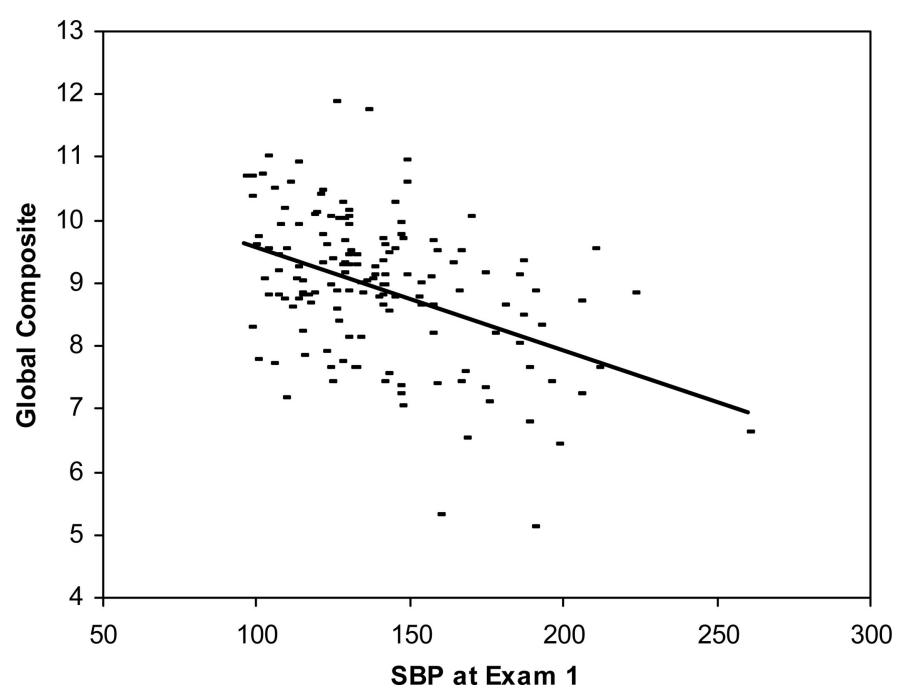

Figure 1. SBP in relation to Global Composite $t$ scores $(z$-score +10$)$ for the African American sample.

ates in the basic model, the regression coefficients for the African Americans and the Caucasian Americans are significant $(\beta=-0.214$ and $\beta=-0.095$ respectively, both $p$ values $<.001)$. However, the presentation of these regression coefficients in bold type means that the SBP by race interaction was also significant. The regression coefficient for the African Americans $(\beta=-0.214)$ was higher in magnitude than the regression coefficient for the Caucasian Americans $(\beta=-0.095)$.

As also may be seen in Table 2, with adjustment for the basic covariate model, SBP was inversely associated with performance on all cognitive measures for Caucasian Americans and with all cognitive measures except for the Digit Span tests for African Americans. Analyses were undertaken to see which covariates in the basic model were responsible for attenuation of crude (unadjusted) regression coefficients between SBP and cognitive performance. Essentially, adjustment for age and education resulted in the greatest attenuation in these relations. For instance, for the association of the

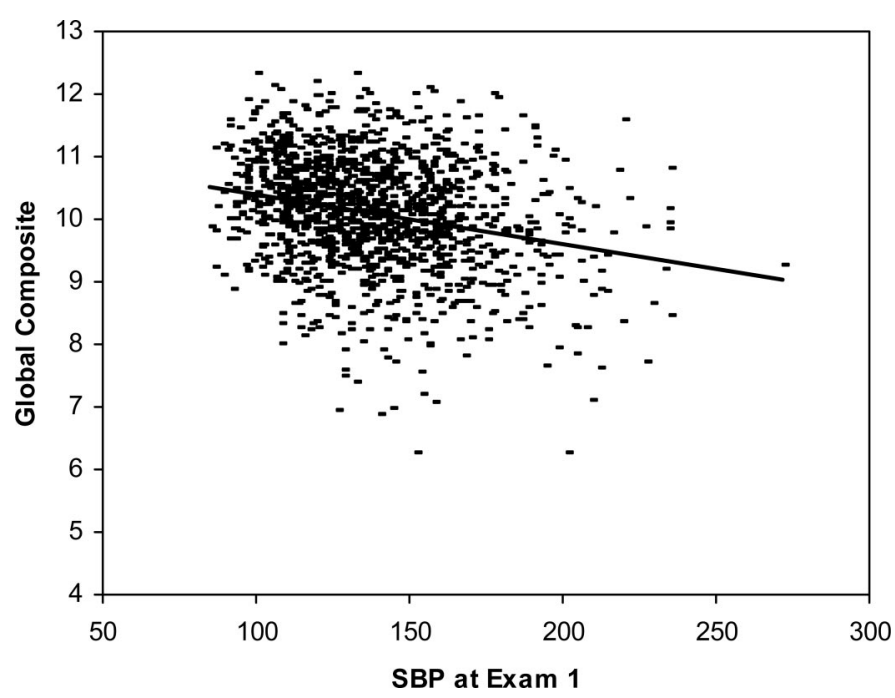

Figure 2. SBP in relation to Global Composite $t$ scores $(\mathrm{z}$-score +10$)$ for the Caucasian-American sample.

Global Composite measure with SBP for African Americans, education and age accounted for the full extent of attenuation from a crude regression coefficient of $\beta=-0.330$ to the value of $\beta=-0.214$ shown in Table 2 .

A comparison of columns 3 and 4 with columns 1 and 2 shows that, although regression coefficients were further attenuated when adjusted for the additional covariates in the expanded model, the pattern of inverse associations between SBP and cognitive performance was essentially the same. The degree of attenuation in regression coefficients for the expanded, as compared with the basic, model was largely attributable to adjustment for the antihypertensive medication use covariate. Again using the example of the association of the Global Composite with SBP for African Americans, adjustment for antihypertensive medication use alone attenuated the regression coefficient of $\beta=-0.214$ for the basic model to $\beta=-0.120$. Adjustment for all covariates in the expanded model resulted in the value of $\beta=-0.114$ shown in column 3 of Table 2 . 
TABLE 2. Regression Coefficients $(\beta)$ Expressing Change in Cognitive Performance (in SD units) per $20 \mathrm{~mm} \mathrm{Hg}$ change in Systolic Blood Pressure

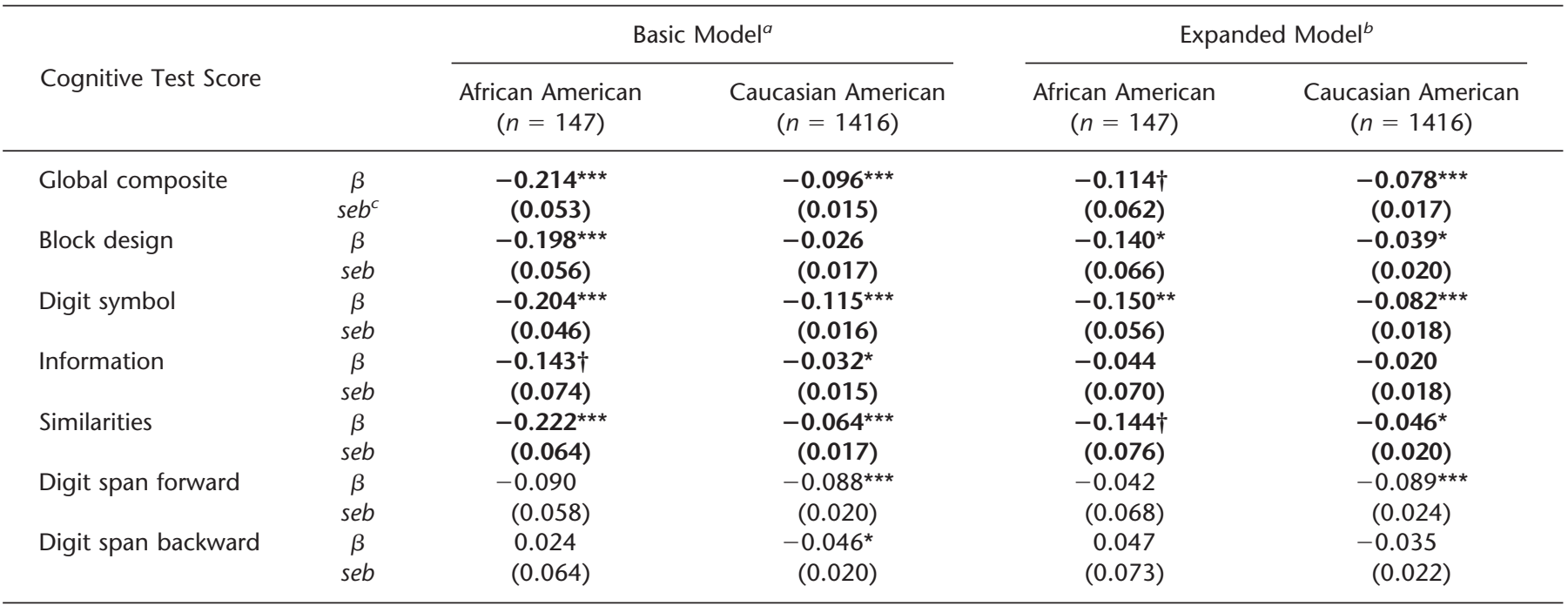

Bold type indicates that the SBP by Race interaction for the cognitive outcome variable was significant $(p<.05)$ in that model.

${ }^{\dagger} p<.08 ; * p<.05 ; * * p<.01 ; * * * p<.001$.

${ }^{a}$ Basic Model $=$ SBP, race, age, education, gender, and occupation.

${ }^{b}$ Expanded Model = SBP, race, age, education, gender, occupation, diabetes, body mass index, depressive symptoms, trait anxiety, anti-hypertensive medication, psychotropic medication, alcohol use, cigarette smoking.

${ }^{c} s e b=$ standard error of $\beta$.

Results for DBP, shown in Table 3, largely mirrored the results for SBP. However, results for pulse pressure diverged from those for SBP and DBP in that for only one cognitive test, Digit Symbol Substitution, was there a significant Pulse Pressure by race interaction $(p<.05)$. This significant interaction was observed for the basic model and the expanded model. With respect to the basic model, the regression of Digit Symbol Substitution scores on pulse pressure was significant for both the African Americans $(\beta=-0.106$; $s e b=0.049$; $p<.05)$ and the Caucasian Americans $(\beta=-0.059$; seb $=$ $0.014 ; p<.001)$. Adjustment for the variables in the expanded model attenuated these regression coefficients for both

TABLE 3. Regression Coefficients Expressing Change in Cognitive Performance (in SD units) per $10 \mathrm{~mm} \mathbf{H g}$ Change in Diastolic Blood Pressure

\begin{tabular}{|c|c|c|c|c|c|}
\hline & & \multicolumn{2}{|c|}{ Basic Model $^{a}$} & \multicolumn{2}{|c|}{ Full Model ${ }^{b}$} \\
\hline & & $\begin{array}{l}\text { African American } \\
\quad(n=147)\end{array}$ & $\begin{array}{l}\text { Caucasian American } \\
\qquad(n=1416)\end{array}$ & $\begin{array}{l}\text { African American } \\
\quad(n=147)\end{array}$ & $\begin{array}{c}\text { Caucasian American } \\
(n=1416)\end{array}$ \\
\hline \multirow[t]{2}{*}{ Global composite } & $\beta$ & $-0.177^{\star \star *}$ & $-0.059 * \star *$ & $-0.115^{\star}$ & $-0.045^{\star \star *}$ \\
\hline & $s e b^{c}$ & $(0.038)$ & $(0.012)$ & $(0.047)$ & $(0.014)$ \\
\hline \multirow[t]{2}{*}{ Block design } & $\beta$ & $-0.155^{* * *}$ & -0.002 & $-0.110^{*}$ & -0.002 \\
\hline & seb & $(0.040)$ & $(0.013)$ & $(0.049)$ & $(0.016)$ \\
\hline \multirow[t]{2}{*}{ Digit symbol } & $\beta$ & $-0.158^{\star * *}$ & $-0.091^{* \star *}$ & $-0.125^{\star *}$ & $-0.065^{\star \star *}$ \\
\hline & seb & $(0.033)$ & $(0.013)$ & $(0.042)$ & $(0.015)$ \\
\hline \multirow[t]{2}{*}{ Information } & $\beta$ & $-0.096^{\star}$ & -0.011 & -0.058 & 0.001 \\
\hline & seb & $(0.042)$ & $(0.012)$ & $(0.052)$ & $(0.014)$ \\
\hline \multirow[t]{2}{*}{ Similarities } & $\beta$ & $-0.167^{\star \star *}$ & $-0.040^{* *}$ & $-0.116^{*}$ & -0.023 \\
\hline & seb & $(0.046)$ & $(0.014)$ & $(0.057)$ & $(0.016)$ \\
\hline \multirow[t]{2}{*}{ Digit span forward } & $\beta$ & $-0.075 \dagger$ & $-0.067^{\star \star \star}$ & -0.056 & $-0.070^{\star * *}$ \\
\hline & seb & $(0.041)$ & $(0.016)$ & $(0.051)$ & $(0.019)$ \\
\hline \multirow[t]{2}{*}{ Digit span backward } & $\beta$ & -0.009 & $-0.030 \dagger$ & 0.002 & -0.023 \\
\hline & seb & $(0.047)$ & $(0.015)$ & $(0.006)$ & $(0.018)$ \\
\hline
\end{tabular}

Bold type indicates that the DBP X Race interaction for the cognitive outcome variable was significant $(p<.05)$ in that model.

${ }^{\dagger} p<.08 ; * p<.05 ; * * p<.01 ; * * p<.001$.

${ }^{a}$ Basic Model $=$ Age, Education, Gender, and Occupation.

${ }^{b}$ Expanded Model = SBP, race, age, education, gender, occupation, diabetes, body mass index, depressive symptoms, trait anxiety, anti-hypertensive medication, psychotropic medication, alcohol use, cigarette smoking.

${ }^{c}$ seb $=$ standard error of $\beta$. 
the African Americans $(\beta=-0.061 ;$ seb $=0.051 ; p>.10)$ and the Caucasian Americans $(\beta=-0.033$; seb $=0.014$; $p<.05)$.

Pulse pressure was related to each cognitive variable, with the exception of Digit Span Backward. These inverse associations between pulse pressure and cognitive performance were obtained for both the basic and expanded models.

\section{DISCUSSION}

Our primary goals for this study were (a) to describe associations between indices of BP and cognitive functioning for an African-American cohort; (b) to compare these results with findings for a Caucasian-American cohort; and (c) to examine possible age by BP interactions within these cohorts. With regard to the latter goal, no significant age by BP interactions were observed. However, as hypothesized, significant inverse linear associations between measures of BP and cognitive functioning were obtained for both racial cohorts. These results were observed when relations between BP and cognitive performance were adjusted for a basic model (age, education, gender, and occupation) and persisted when adjusted for the expanded covariate model which included cardiovascular risk factor variables. These results also persisted when the sample was expanded to include individuals with a history of hypertension-related comorbidity and other major disease.

The majority of these inverse associations were higher in magnitude for the African-American cohort than for the Caucasian-American cohort. These included relations of both SBP and DBP to four of the WAIS test scores (Block Design, Digit Symbol Substitution, Information, and Similarities), and the Global Composite. The only WAIS tests for which associations with SBP and DBP did not differ between the racial cohorts were the Digit Span tests. However, the magnitude of inverse associations between pulse pressure values and cognitive functioning did not generally differ between the racial cohorts, with one exception. For the African Americans, compared with the Caucasian Americans, pulse pressure exhibited a higher magnitude of association with Digit Symbol Substitution scores.

The pattern of BP effects observed in our investigation is consistent with the literature indicating that hypertension and increments in BP are associated with poorer performance in multiple cognitive domains. Cognitive domains for which associations of BP and cognitive performance are consistently observed and tend to be high in magnitude include abstract reasoning, psychomotor, and visual organization abilities $(6,7,26,33)$.

The cognitive test for which the strongest and most consistent associations between BP measures and cognition were obtained in this study was Digit Symbol Substitution, a measure of psychomotor speed $(34,35)$. Inverse associations were obtained for each BP measure and both racial groups. Results very similar to those for Digit Symbol Substitution were observed for the Similarities test, which places demands on concept formation and abstract reasoning abilities $(29,34)$.
Inverse associations of SBP and DBP with Digit Symbol Substitution and Similarities were higher in magnitude for African Americans than for Caucasian Americans. This result was also obtained for Block Design, a measure of visualorganizational abilities (34).

The WAIS tests showing significant relationships with BP measures assess the cognitive domains that are most likely to show disproportionate decrement in relation to vascular cognitive impairment (36) and vascular dementia $(37,38)$. Vascular dementia is relatively more common for African Americans than Caucasian Americans (11). Thus the pattern of results is consistent with the view that these BP-related decrements in cognitive function may be early signs of a process which, in the absence of intervention, can gradually progress to vascular-related cognitive impairment (39).

The major limitations of the present study are that the data are cross-sectional and we employed relatively well-educated individuals. The absence of BP by age interactions, and curvilinear associations of $\mathrm{BP}$, in relation to cognitive performance may be attributable to the fact that this was, on average, a relatively young and well educated sample.

Results of this study indicate that, as is true for Caucasian Americans, for African Americans high BP is related to poorer performance in multiple cognitive domains. Because there is a higher prevalence and incidence of elevated BP among African Americans across the life span (9), further investigation of potential effects of high BP on cognitive functioning among African Americans should be conducted using prospective and longitudinal designs. Cross-sectional designs may produce an under estimation of the long-term effects of high BP on cognitive functioning (33).

Aggressive efforts toward preventing, detecting, and controlling hypertension in the African-American population may help preserve cardiovascular health and cognitive abilities (40). Although much that is done in this regard applies to everyone, regardless of race, further research on socioeconomic and psychosocial factors that might disproportionately affect the cardiovascular health of African Americans (41-45) is warranted.

We wish to thank Gregory Dore and Dawn Norris for technical assistance.

\section{REFERENCES}

1. Fields LE, Burt VL, Cutler JA, Hughes J, Roccella EJ, Sorlie P. The burden of adult hypertension in the United States 1999 to 2000: A rising tide. Hypertension 2004;44:398-404.

2. Hajjar I, Kotchen TA. Trends in prevalence, awareness, treatment, and control of hypertension in the United States, 1988-2000. JAMA 2003; 290:199-206.

3. Katzel LI, Waldstein SR. Classification of cardiovascular disease. In: Waldstein SR, Elias MF, editors. Neuropsychology of cardiovascular disease. Mahwah, NJ: Lawrence Erlbaum Associates; 2001. p. 3-14.

4. Klag MJ, Whelton PK, Randall BL, Neaton JD, Brancati FL, Stamler J. End stage renal disease in African-American and white men: 16-year MRFIT findings. JAMA 1997;277:1293-8.

5. Stamler J. Established major coronary risk factors. In: Marmot M, Elliott P, editors. Coronary heart disease epidemiology. New York: Oxford University Press; 1992. p. 35-65.

6. Elias MF, Robbins MA, Budge MM, Elias PK, Hermann BA, Dore GA. Studies of aging, hypertension and cognitive functioning, with contribu- 
tions from the Maine-Syracuse study. In: Costa PT, Siegler IC, editors. Advances in cell aging and gerontology, Vol. 15, Recent advances in psychology and aging. Amsterdam: Elsevier; 2004. p. 89-131.

7. Waldstein SR, Katzel LI. Hypertension and cognitive function. In: Waldstein SR, Elias MF, editors. Neuropsychology of cardiovascular disease. Mahwah, NJ: Lawrence Erlbaum Associates; 2001. p. 15-36.

8. Izquierdo-Porrera AM, Waldstein SR. Cardiovascular risk factors and cognitive function in African Americans. J Gerontol B Psychol Sci Soc Sci 2002;57B:P377-80

9. Cooper R, Rotimi C. Hypertension in blacks. Am J Hypertens 1997;7: $804-12$.

10. Flack JM, Nasser SA. Ethnicity and socioeconomic status in hypertension. In: Izzo JL Jr., Black HR, editors. Hypertension primer: the essentials of high blood pressure. Dallas, TX: American Heart Association; 2003. p. 261-264.

11. Larson EB, Imai Y. An overview of dementia and ethnicity with special emphasis on the epidemiology of dementia. In: Yeo G, GallagherThompson D, editors. Ethnicity and the dementias. Washington, DC: Taylor and Francis; 1996. p. 9-20.

12. Williams DR. Racial variations in adult health status: patterns, paradoxes, and prospects. In: Smelser NJ, Wilson WJ, Mitchell F., editors. America becoming: Racial trends and their consequences. Washington (DC): National Academy Press (Vol. II); 2001. p. 371-410.

13. Winkleby MA, Kraemer HC, Ahn DK, Varady AN. Ethnic and socioeconomic differences in cardiovascular disease risk factors: findings for women from the Third National Health and Nutrition Examination Survey, 1988-1994. JAMA 1998;280:356-62.

14. Bohannon AD, Fillenbaum GG, Pieper CF, Hanlon JT, Blazer DG. Relationship of race/ethnicity and blood pressure to change in cognitive function. J Am Geriatr Soc 2002;50:424-9.

15. Knopman D, Boland LL, Mosley T, Howard G, Liao D, Szklo M, McGovern P, Folsom AR. For the Atherosclerosis Risk in Communities (ARIC) Study Investigators. Cardiovascular risk factors and cognitive decline in middle-aged adults. Neurology 2001;56:42-8.

16. Morris MC, Scherr PA, Hebert LE, Bennett DA, Wilson RS, Glynn RJ, Evans DA. Association between blood pressure and cognitive function in a biracial community population of older persons. Neuroepidemiology 2002;21:123-30

17. Suhr JA, Stewart JC, France CR. The relationship between blood pressure and cognitive performance in the Third National Health and Nutrition Examination Survey (NHANES III). Psychosom Med 2004;66:291-7.

18. Waldstein SR. Hypertension and neuropsychological function: a lifespan perspective. Exp Aging Res 1995;21:321-52.

19. Elias MF, Robbins MA, Schultz NR Jr, Pierce TW. Is blood pressure an important variable in research on aging and neuropsychological test performance? J Gerontol B Psychol Sci Soc Sci 1990;45:128-35.

20. Madden DJ, Blumenthal JA. Interaction of hypertension and age in visual selective attention performance. Health Psychol 1998;17:76-83

21. Waldstein SR, Jennings JR, Ryan CM, Muldoon MF, Shapiro AP, Polefrone JM, Fazzari TV, Manuck SB. Hypertension and neuropsychological performance in men: interactive effects of age. Health Psychol 1996;15:102-9.

22. Wilkie FL, Eisdorfer C. Intelligence and blood pressure in the aged. Science 1971;172:959-62.

23. Elias PK, Elias MF, Robbins MA, Budge, MM. Blood pressure-related cognitive decline: does age make a difference? Hypertension 2004;44: 631-6.

24. Streeten DHP, Anderson GH Jr, Elias MF. Prevalence of secondary hypertension and unusual aspects of the treatment of hypertension in elderly individuals. Geriatr Nephrol Urol 1992;2:91-8.
25. Spielberger CD, Gorsuch L, Lushene RE. STAI manual for the State/ Trait Anxiety Inventory. Palo Alto, CA: Consulting Psycholgists Press; 1970.

26. Zung, WWK. A self-rating depression scale. Arch Gen Psychiatry 1965; $12: 63-70$.

27. Brodman K, Erdmann AJ, Wolff HG. Cornell Medical Index Health Questionnaire. Ithaca, NY: Cornell University Medical College; 1956.

28. Shapiro D, Jamner LD, Lane JD, Light KC, Myrtek M, Sawada Y, Steptoe A. Blood pressure publication guidelines. Society for Psychophysical Research. Psychophysiology 1996;33:1-12.

29. Wechsler D. The measurement and appraisal of adult intelligence. Manual for the Wechsler Adult Intelligence Scale. New York: Psychological Corporation; 1955.

30. Pedhazur, EJ. Multiple regression in behavioral research: explanation and prediction. 2nd edition. New York: CBS College Publishing; 1982.

31. Stevens J. Applied multivariate statistics for the social sciences. 3rd edition. Mahwah, NJ: Lawrence Erlbaum Associates; 1996.

32. Chobanian AV, Bakris GL, Black HR, Cushman WC, Green LA, Izzo JL Jr, Jones DW, Materson BJ, Oparil S, Wright JT Jr, Roccella EJ. Seventh report of the Joint National Committee on Prevention, Detection, Evaluation, and Treatment of High Blood Pressure. Hypertension 2003;42: $1206-52$.

33. Waldstein SR. Health effects on cognitive aging. In: Stern PC, Carstensen LL, editors. The Aging Mind. Washington, DC: Committee of Future Directions for Cognitive Research on Aging, Board on Behavioral, Cognitive and Sensory Sciences, Commission on Behavioral and Social Sciences and Education, National Research Council; 2000. p. 189-217.

34. Lezak MD. Neuropsychological assessment. 3rd edition. New York: Oxford University Press; 1995.

35. Salthouse TA. What do adult age differences in the Digit Symbol Substitution Test reflect? J Gerontol B Psychol Sci Soc Sci 1992;47:121-8.

36. Bowler JV, Hachinski V. Vascular cognitive impairment: a new approach to vascular dementia. Baillieres Clin Neurol 1995;4:357-76.

37. Desmond DW. Vascular dementia: a construct in evolution. Cerebrovasc Brain Metab Rev 1996;8:296-325

38. Knopman D, Selnes O. Neuropsychology of dementia. In: Heilman K, Valenstein E, editors. Clinical neuropsychology. New York: Oxford University Press, Inc.; 2003. p. 574-616.

39. Elias MF, Sullivan LM, D'Agostino RB, Elias PK, Beiser A, Au R, Seshadri S, DeCarli C, Wolf PA. Framingham stroke risk profile and lowered cognitive performance. Stroke 2004;35:404-9.

40. Murray MD, Lane KA, Gao S, Evans RM, Unverzagt FW, Hall KS, Hendrie $H$. Preservation of cognitive function with antihypertensive medications. Arch Int Med 2002;162:2090-6.

41. Anderson NB, Myers HF, Pickering T, Jackson JS. Hypertension in blacks: psychosocial and biological perspectives. J Hypertens 1989;7: 161-72.

42. Harris KF, Matthews KA. Interactions between autonomic nervous system activity and endothelial function: a model for the development of cardiovascular disease. Psychosom Med 2004;66:153-64.

43. Krieger N, Sidney S. Racial discrimination and blood pressure: the CARDIA study of young black and white adults. Am J Public Health 1996;86:1370-78.

44. Steffen PR, McNeilly M, Anderson N, Sherwood A. Effects of perceived racism and anger inhibition on ambulatory blood pressure in African Americans. Psychosom Med 2003;65:746-50.

45. Strogatz DS, Croft JB, James SA, Keenan NL, Browning SR, Garrett JM, Curtis AB. Social support, stress, and blood pressure in black adults. Epidemiology 1997;8:482-487. 